Vol 12, Issue 2, 2019

\title{
PHYTOCHEMICAL SCREENING AND ANTIOXIDANT ACTIVITY OF ECLIPTA ALBA L.
}

\author{
THENMOZHI M*, JAYANTHI M
}

Department of Biotechnology, Vels Insititute of Science, Technology and Advanced Studies, Pallavaram, Chennai, Tamil Nadu, India. Email: drmthenmozhi@gmail.com

Received: 08 June 2018, Revised and Accepted: 17 October 2018

ABSTRACT

Objective: Earlier various studies on pharmacological and therapeutic properties of Eclipta alba L. have been reported. The present investigation is on phytochemical screening and antioxidant activity of $E$. alba L. using different solvent extracts.

Method: The shade-dried and grounded E. alba L. plant materials were treated with petroleum ether, chloroform, ethyl acetate, ethanol, methanol, and water (aqueous) solvents. The extracted residue was then dissolved in dimethylsulfoxide and further used for phytochemical screening and antioxidant studies.

Results: $E$. alba L. on different solvent extract, the extractive yield was higher in methanol $(14.22 \pm 0.99 \% \mathrm{w} / \mathrm{w})$. The phytochemical screening analysis showed high number of secondary metabolites in the aqueous extract compared to other solvent studied. The metabolite flavonoids, phenols, and tannins are likely to be antioxidant potential compound. Hence, further, the total flavonoid content determination showed high of $0.875 \pm 0.020 \mu \mathrm{g} / \mathrm{g}$ in methanol extract. Further antioxidant property of $E$. alba L. was studied by method such as1,1-diphenyl-2-picrylhydrazyl radical scavenging activity, nitric oxide scavenging activity, metal chelating activity, and superoxide dismutase activity which showed high antioxidant potency with $\mathrm{IC}_{50}$ values of $62.76 \pm 0.63 \mu \mathrm{g} / \mathrm{ml}, 96.24 \pm 0.34 \mu \mathrm{g} / \mathrm{ml}, 72.29 \pm 0.61 \mu \mathrm{g} / \mathrm{ml}$, and $108.40 \pm 0.52 \mu \mathrm{g} / \mathrm{ml}$, respectively, in the petroleum ether extract.

Conclusion: From the present study, the substantiate result of antioxidant studies has been obtained from petroleum ether extract. Furthermore the extractive value and flavonoid content was observed to be high in methanol extract. The antioxidant potency of $E$. alba L. was found to be high in petroleum ether extract compared to other solvent studied.

Keywords: Eclipta alba L., Methanol, Antioxidant, Flavonoid, 1,1-diphenyl-2-picrylhydrazyl, Radical scavenging.

(C) 2019 The Authors. Published by Innovare Academic Sciences Pvt Ltd. This is an open access article under the CC BY license (http://creativecommons. org/licenses/by/4. 0/) DOI: http://dx.doi.org/10.22159/ajpcr.2019.v12i2.27828

\section{INTRODUCTION}

Eclipta alba L. is small branched annual herbaceous plant with a long history of traditional medicines uses in many countries, especially in tropical and subtropical regions. E. Alba is a source of coumestan-type compounds used in pharmaceutical formulations of medicines prescribed for the treatment of cirrhosis of the liver and infectious hepatitis [1].

E. alba is traditionally used for blackening, promoting hair growth, and strengthening the hair. It is used as antivenom against snake bite in China and Brazil. The herb has been known for its curative properties and has been utilized as antimytotoxic, analgesic, antibacterial, antihepatotoxic, antihemorrhagic, antihyperglycemic, antioxidant, and immunomodulatory properties, and it is considered as a good rejuvenator too.

Phytochemical constituents are the basic source for the establishment of several pharmaceutical industries. The constituents are playing a significant role in the identification of crude drugs. Therefore, proper scientific knowledge is required to investigate and explore the exact standardization of such medicinally important plant.

Moreover, plant-based medicines also have an enormous potential to provide low cost, easily accessible, and safe method of treatment. Herbal medicines are widely accepted in complementary and alternative medicine, especially in cancer patients with poor socioeconomic condition. Hundreds of plants possessing anticancer properties have been identified, and they are the source of alternative medicine for cancer therapy in various regions of the globe [2].

The medicinal properties of plants have been investigated in the recent scientific developments throughout the world, due to their potent antioxidant activities, no side effects, and economic viability [3].

\section{METHODS}

Plant collection and identification of plants

The plants used in this study E. alba L. Hassk No. BSI/SRC/5/23/1011/Tech-706 (Asteraceae) was collected from Namakkal District, Tamil Nadu, and it was authenticated at the Botanical Survey of India, South Circle, Coimbatore, Tamil Nadu.

E. alba (L.) Hassk

Kingdom: Plantae

Order: Asterales

Family: Asteraceae

Genus: Eclipta

Species: $E$. alba

\section{Preparation of powder}

The E. alba L. was collected and dried under shade without any contamination [4]. These dried materials were mechanically powdered, sieved using $80 \mathrm{~mm}$ mesh, and stored in airtight containers. These powdered materials were used for further extraction analysis.

\section{Extraction for analysis}

The dried plants of E. alba L. were powdered and treated with different solvents, namely petroleum ether, chloroform, ethyl acetate, ethanol, methanol, and water (aqueous). The solvents were evaporated and residues were dissolved in dimethylsulfoxide (DMSO). It was used for the phytochemical and antioxidant activity.

\section{Preliminary phytochemical screening}

Phytochemical screening was performed for the analysis of different phytoconstituents such as carbohydrates, proteins, steroids, amino acids, glycosides, alkaloids, flavonoids, vitamins, saponins, tannins and 
phenol compounds, quinones, and fixed oils and fats. The screening was performed with some modifications of the method [5].

\section{Determination of antioxidant activity}

Antioxidants are compounds that inhibit oxidation. Oxidation is a chemical reaction that can produce free radicals, thereby leading to chain reactions that may damage the cells of organisms. Some of the mechanisms are by donating a hydrogen atom or electron to the radical, scavenging free radical, chelating metal ions, inhibiting $\beta$-carotene bleaching, and quenching singlet oxygen. Each assay specifically detects any one of the abilities of the antioxidant. Therefore, it is necessary to use more than one type of antioxidant assay [6].

\section{Determination of total flavonoids}

The amount of flavonoids was determined spectrophotometrically [7]. $1 \mathrm{ml}$ of plant extract was mixed with $1 \mathrm{ml}$ of $2 \%$ aluminum trichloride in ethanol. The mixture was diluted with ethanol to $25 \mathrm{ml}$ and allowed to stand for $40 \mathrm{~min}$ at $20^{\circ} \mathrm{C}$, and the absorbance was measured at $415 \mathrm{~nm}$ against the sample blank. The results were expressed as quercetin equivalent per gram of dried sample.

\section{1,1-diphenyl-2-picrylhydrazyl (DPPH) radical scavenging assay}

The radical scavenging activity of plant extracts and ascorbic acid was measured by the DPPH method [8]. $1 \mathrm{ml}$ of $0.135 \mathrm{mM}$ DPPH solution in methanol was mixed with $1 \mathrm{ml}$ of extract. The reaction mixture was vortexed and left in the dark at room temperature for $30 \mathrm{~min}$. The absorbance was measured at $517 \mathrm{~nm}$. A reaction mixture without test sample served as control. The ability to scavenge DPPH radical was calculated by the following equation:

DPPH radical scavenging activity $(\%)=\frac{\left[\left(\mathrm{Abs}_{\text {control }}-\mathrm{Abs}_{\text {sample }}\right)\right]}{\left(\mathrm{Abs}_{\text {control }}\right)} \times 100$

Nitric oxide (NO) radical scavenging activity

NO radical scavenging activity was measured by spectrophotometric method [9]. Test samples at different concentrations (1000-9000 $\mu \mathrm{g}$ ) were dissolved in DMSO. With $1 \mathrm{ml}$ of the test solution, $1 \mathrm{ml}$ of sodium nitroprusside $(5 \mathrm{~mm})$ in phosphate buffer saline was mixed and incubated for $30 \mathrm{~min}$ at $25^{\circ} \mathrm{C}$. An assay medium without test solution served as control. After $30 \mathrm{~min}, 1 \mathrm{ml}$ of incubated solution was taken out and an equal amount of Griess reagent was added. The absorbance of the chromophore formed during the diazotization of the nitrile with sulfanilamide and the subsequent coupling with naphthyl ethylenediamine dihydrochloride was measured at $546 \mathrm{~nm}$. Catechin was used for comparison. The percentage scavenging activity was calculated as follows:

Nitric oxideradicalscavenging activity $(\%)=$

$\frac{\left[\left(\mathrm{Abs}_{\text {control }}-\mathrm{Abs}_{\text {sample }}\right)\right]}{\left(\mathrm{Abs}_{\text {control }}\right)} \times 100$

\section{$\mathrm{Fe}^{2+}$ chelating activity}

Ferrous ion chelating activity assay was based on the principle of the $\mathrm{Fe}^{2+}$ chelating ability of the test samples by measuring the ferrous ironferrozine complex formed at $562 \mathrm{~nm}$ [10]. Two different concentrations of sample extracts were added to $0.1 \mathrm{ml}$ of $2 \mathrm{mM}$ ferrous chloride, $0.2 \mathrm{ml}$ of $5 \mathrm{mM}$ ferrozine, and $3.7 \mathrm{ml}$ of methanol. The solution was allowed to react for $10 \mathrm{~min}$. The absorbance at $562 \mathrm{~nm}$ was measured against blank. The chelating activity of the extracts on $\mathrm{Fe}^{2+}$ was compared with that of ethylenediaminetetraacetic acid (EDTA) $(0.01 \mathrm{mM})$ and citric acid $(0.025 \mathrm{M})$. The percentage of ferrous ion chelating activity was calculated as follows:

$\mathrm{Fe}^{2+}$ Chelation activity $(\%)=\frac{\left[\left(\mathrm{Abs}_{\text {control }}-\mathrm{Abs}_{\text {sample }}\right)\right]}{\left(\mathrm{Abs}_{\text {control }}\right)} \times 100$
Superoxide dismutase (SOD)

Superoxide scavenging activity was based on the inhibitory action of SOD on the rate of base-catalyzed autoxidation of pyrogallol [11]. The assay medium contained $1 \mathrm{ml}$ of different concentrations of the test sample, $2 \mathrm{ml}$ of water, $3 \mathrm{ml}$ of $0.05 \mathrm{M}$ Tris buffer, and $\mathrm{pH} \mathrm{8.2,} \mathrm{and} \mathrm{the}$ reaction was initiated by the addition of $0.02 \mathrm{ml}$ of pyrogallol $(60 \mathrm{~mm})$ and the reading was recorded every $1 \mathrm{~min}$ at $420 \mathrm{NM}$. The chelating activity of the extracts on SOD was compared with that of quercetin. The percentage of superoxide scavenging activity was calculated as follows:

Superoxide scavenging activity $(\%)=\frac{\left[\left(\mathrm{Abs}_{\text {control }}-\mathrm{Abs}_{\text {sample }}\right)\right]}{\left(\mathrm{Abs}_{\text {control }}\right)} \times 100$

\section{RESULTS AND DISCUSSION}

Extractive values for different solvents

The extractive values are successive with petroleum ether, chloroform, ethyl acetate, ethanol, methanol, and aqueous extract, and their percentage yield was calculated (Table 1). The increased amount of extract value indicates more solubility of the phytoconstituents. In the present study, methanol extract has shown a higher amount of value compared to all other extracts, followed by ethanol, chloroform, aqueous, and petroleum ether. Very poor extract value was observed in ethyl acetate. Based on the solvent polarity and extraction method, the

Table 1: Solvent extraction methods and yield from powder of Eclipta alba L.

\begin{tabular}{lll}
\hline S. No & Extracts & $\begin{array}{l}\text { Extractive values } \\
\text { in } \%(\mathbf{W} / \mathbf{W})\end{array}$ \\
\hline 1 & Petroleum ether & $8.01 \pm 0.18$ \\
2 & Chloroform & $12.58 \pm 0.24$ \\
3 & Ethyl acetate & $7.87 \pm 0.15$ \\
4 & Ethanol & $12.97 \pm 0.12$ \\
5 & Methanol & $14.22 \pm 0.19$ \\
6 & Aqueous & $11.35 \pm 0.10$ \\
\hline Data represented a mean + SE SE. Standard error &
\end{tabular}

Table 2: Preliminary phytochemical screening of Eclipta alba L.

\begin{tabular}{|c|c|c|c|c|c|c|c|}
\hline \multirow[t]{2}{*}{ S.No } & \multirow[t]{2}{*}{ Constituents } & \multicolumn{6}{|c|}{ Extracts } \\
\hline & & PE & $\mathrm{CH}$ & EA & ET & ME & AQ \\
\hline 1 & Carbohydrates & + & + & + & + & + & + \\
\hline 2 & Proteins & + & + & + & + & + & + \\
\hline 3 & Steroids & + & - & + & - & - & + \\
\hline 4 & Amino acids & + & + & + & + & + & + \\
\hline 5 & Glycosides & + & + & + & + & + & + \\
\hline 6 & Alkaloids & - & + & - & - & + & + \\
\hline 7 & Flavonoids & + & + & + & + & + & + \\
\hline 8 & Saponins & - & + & - & + & - & + \\
\hline 9 & Tannins and phenol compounds & + & + & + & + & + & + \\
\hline 10 & Quinones & + & - & + & - & + & + \\
\hline 11 & Fixed oils and fats & + & + & + & + & + & + \\
\hline 12 & Terpenes & - & - & - & - & - & - \\
\hline
\end{tabular}

+: Presence, - : Absence of phytochemicals. PE: Petroleum ether, CH: Chloroform, EA: Ethyl acetate, ET: Ethanol, ME: Methanol, AQ: Aqueous

Table 3: Flavonoid content of Eclipta alba L.

\begin{tabular}{lll}
\hline S.NO & Extracts & $\begin{array}{l}\text { Content mg/g dry } \\
\text { weight }\end{array}$ \\
\hline 1 & Petroleum ether & $0.420 \pm 0.014$ \\
2 & Chloroform & $0.793 \pm 0.009$ \\
3 & Ethyl acetate & $0.666 \pm 0.014$ \\
4 & Ethanol & $0.714 \pm 0.009$ \\
5 & Methanol & $0.875 \pm 0.020$ \\
6 & Aqueous & $0.608 \pm 0.011$ \\
\hline \multicolumn{2}{l}{ Data are represented as mean+SE. SE: Standard error }
\end{tabular}


Table 4: Antioxidant property of Eclipta alba L.

\begin{tabular}{|c|c|c|c|c|c|}
\hline \multirow[t]{2}{*}{ S.No } & \multirow[t]{2}{*}{ Extracts } & \multicolumn{4}{|l|}{$\mathrm{IC}_{50}(\mu \mathrm{g} / \mathrm{ml})$} \\
\hline & & $\begin{array}{l}\text { DPPH } \\
\text { Activity }\end{array}$ & $\begin{array}{l}\text { NO scavenging } \\
\text { activity }\end{array}$ & $\begin{array}{l}\mathrm{Fe}^{2+} \text { Chelating } \\
\text { activity }\end{array}$ & $\begin{array}{l}\text { SOD } \\
\text { activity }\end{array}$ \\
\hline 1. & Petroleum ether & $65.76 \pm 0.63$ & $96.24 \pm 0.34$ & $72.29 \pm 0.61$ & $108.40 \pm 0.52$ \\
\hline 2. & Chloroform & $39.23 \pm 0.71$ & $52.68 \pm 0.58$ & $44.18 \pm 0.46$ & $68.76 \pm 0.56$ \\
\hline 3. & Ethyl acetate & $50.68 \pm 0.55$ & $63.82 \pm 0.43$ & $52.24 \pm 0.49$ & $83.89 \pm 0.76$ \\
\hline 4. & Ethanol & $43.88 \pm 0.76$ & $59.67 \pm 0.56$ & $48.51 \pm 0.39$ & $77.34 \pm 0.56$ \\
\hline 5. & Methanol & $33.10 \pm 0.38$ & $44.10 \pm 0.45$ & $32.74 \pm 0.55$ & $55.74 \pm 0.63$ \\
\hline 6. & Aqueous & $54.21 \pm 0.61$ & $72.76 \pm 0.69$ & $62.16 \pm 0.71$ & $92.93 \pm 0.59$ \\
\hline
\end{tabular}

Mean \pm SE. SE: Standard error, DPPH: 1,1-diphenyl-2-picrylhydrazyl, SOD: Superoxide dismutase

yield of phytoconstituents/extract differs significantly [12,13]. Similar to our present study, extract yield was found to be high in methanol in Eclipta prostrata L. [14]. It has been reported that extract yield was found to be high in methanol [14].

\section{Phytochemical screening}

The present study revealed that the carbohydrates, proteins, amino acids, glycosides, flavonoids, tannin and phenol compound, and fixed oils and fats present in all extracts (Table 2). However, the steroids were present only in petroleum ether, ethyl acetate, and aqueous extracts. Alkaloids were present in chloroform, methanol, and aqueous extracts. Saponins were present in chloroform, ethanol, and aqueous extracts. Quinones were present in petroleum ether, ethyl acetate, methanol, and aqueous extracts. Terpenes were determined to be absent in all the extracts. Compared to all other solvent extracts, aqueous extracts were shown high values of secondary metabolites. Phytochemical screening using different solvents has been reported on this plant $[15,16]$. The phytoconstituents such as flavonoids, tannins, and phenolic compound extracts were liable for its antioxidant property.

\section{Determination of total flavonoid content}

Medicinal plants are an important source of antioxidants [17]. Natural antioxidants increase the antioxidant capacity of the plasma and reduce the risk of certain diseases [18]. Flavonoids are phenolic acids, which serve as an important source of antioxidants found in different medicinal plants and related phytomedicines [19]. The antioxidant activity of flavonoids is due to their ability to reduce free radical formation and scavenge free radicals. The total flavonoid content analysis of the present study was found higher in the methanolic extract $(0.875 \pm 0.020 \mathrm{mg} / \mathrm{g})$ followed by chloroform $(0.793 \pm 0.009 \mathrm{mg} / \mathrm{g})$ and ethanol $(0.714 \pm 0.009 \mathrm{mg} / \mathrm{g})$ (Table 3).

Flavonoids are one of the secondary metabolites of medicinal herbs and it is also known as Vitamin P [20]. It is also found to have anti-inflammatory, and anticancer activity [21]. The total flavonoid content was determined and expressed as mg against the standard equivalents quercetin.

\section{DPPH radical scavenging activity}

The antioxidant potential of different solvent extracts of E. alba was determined using DPPH radical scavenging activity. DPPH is nitrogencentered, stable free radical which accepts an electron or hydrogen when reacts with a suitable reducing agent, The sample gets decolorized when reacts its DPPH, which represents the reducing activity [22,23]. The antioxidant potency of the sample along with ascorbic acid revealed the radical scavenging activity with $\mathrm{IC}_{50}$ values of $13.58 \pm 0.38 \mu \mathrm{g} / \mathrm{ml}$ (Table 4 ). The DPPH radical scavenging activity of crude drug showed the highest percentage of antioxidant activity with $\mathrm{IC}_{50}$ values of $65.76 \pm 0.63 \mu \mathrm{g} / \mathrm{ml}$, $54.21 \pm 0.61 \mu \mathrm{g} / \mathrm{ml}$, and $50.68 \pm 0.55 \mu \mathrm{g} / \mathrm{ml}$ in petroleum ether, aqueous, and ethyl acetate extract, respectively. From the overall solvent, a comparison study reveals that maximum radical scavenging activity was shown in the petroleum ether extract followed by aqueous extract and minimum activity was shown in methanol extract.

\section{NO scaveng ing activity}

The NO scavenging activity of the present study was performed against standard catechin. Maximal percentage of scavenging activity along with catechin standard was observed in petroleum ether extract with $\mathrm{IC}_{50}$ value of $96.24 \pm 0.34 \mu \mathrm{g} / \mathrm{ml}$, followed by aqueous and ethyl acetate extract with $\mathrm{IC}_{50}$ value of $72.76 \pm 0.69$ and $63.82 \pm 0.43 \mu \mathrm{g} / \mathrm{ml}$, respectively (Table 4). The structure and function of cells may be altered due to excess generation of NO in tissues [24]. The concentration of NO depends on the disease affection [25]. Flavonoid and phenol phytoconstituents are the cause for the observed NO scavenging activity of our study.

\section{$\mathrm{Fe}^{2+}$ chelating activity}

In the present study, iron chelating activity of petroleum ether, chloroform, ethyl acetate, ethanol, methanol, and aqueous extracts of E. alba $\mathrm{L}$ was determined against standard EDTA. Maximum $\mathrm{IC}_{50}$ value of $72.29 \pm 0.61 \mu \mathrm{g} / \mathrm{ml}$ was observed in the petroleum ether extract, and the minimum chelating activity was observed in the methanol extract with $\mathrm{IC}_{50}$ values of $32.74 \pm 0.55 \mu \mathrm{g} / \mathrm{ml}$ (Table 4).

The present study illustrates that antioxidant property and metal chelating properties of plant extract are may be due to flavonoid content. $\mathrm{Fe}^{2+}$, a transition metal ion, transfers a single electron during the propagation of radical reaction with relatively non-reactive radicals [26]. Chelating agents functions as a secondary antioxidant, by reducing redox potential and stabilizing metal ion oxidation, while metal bonding [27].

\section{SOD activity}

Cellular enzyme SOD was studied in the present study to determine radical scavenging activity property. Table 4 depicts the scavenging activity of E. alba different solvent extracts against standard rutin, which showed $\mathrm{IC}_{50}$ of $32 \pm 0.69 \mu \mathrm{g} / \mathrm{ml}$. The highest percentage of activity was observed in the petroleum ether extract ( $\mathrm{IC}_{50}=108.40 \pm 0.52 \mu \mathrm{g} / \mathrm{ml}$ ). The least percentage radical scavenging activity was observed in the methanol extract $\left(\mathrm{IC}_{50}=55.74 \pm 0.63 \mu \mathrm{g} / \mathrm{ml}\right)$. Reactive oxygen species protect the living system by antioxidant enzymes such as SOD, catalase, lipid peroxide, and other endogenous antioxidant sources [15]. SOD is a potent enzymatic antioxidant defense system [28]. Very high and significant correlation was observed between reducing power and antioxidant activity. A similar relationship was also found between antioxidant potential and reducing the power of different plant extract [29].

\section{CONCLUSION}

It can be concluded from the study that the petroleum ether extract showed significant antioxidant potential compared to other solvent extract studied. However, the extracted value was high in methanol extract. Thus, the potency may be due to the presence of polyphenolic compound (flavonoid). Further studies may reveal the potential of E.alba L.

\section{AUTHORS' CONTRIBUTIONS}

Thenmozhi M: Corresponding author, research work, and typing, Jayanthi M: Suggestion and correction.

\section{CONFLICTS OF INTEREST}

The authors have no conflicts of interest. 


\section{REFERENCES}

1. Selvamani $\mathrm{S}$, Balamurugan $\mathrm{S}$. In vitro antibacterial activity of Eclipta alba (L.) Hassk. Int Lett Nat Sci 2014;21:28-34.

2. Navneet KY, Rakesh KA, Kapil D, Chetan S, Zakir H, et al. Alcoholic extract of Eclipta alba L. Shows in vitro antioxidant and anticancer activity without exhibiting toxicological effects. Oxid Med Cell Longevity 2017;2017:1-18.

3. Regupathi T, Chitra K. In vitro antioxidant properties of Eclipta alba (L.) Hassk. And Lippia nodiflora Linn. Int J Pharm Phytopharm Res 2015;4:227-30.

4. Harborne JB. Phytochemical Methods. London: Chapman and Hall Ltd.; 1973. p. 49-188.

5. Harborne JB. Phytochemical Methods. London: Chapman and Hall Ltd.; 1984. p. 49-188.

6. Sathvika C, Swathi MS, Mangamoori LN. Phytochemical screening and in vitro antioxidant activity of whole plant extracts of Sesuvium portulacastrum L. Asian J Pharm Clin Res 2018;11:322-7.

7. Miliauskas G, Venskutonis P, Van Beek T. Screening of radical scavenging activity of some medicinal and aromatic plant extracts. Food Chem 2004;85:231-7.

8. Liyana-Pathirana CM, Shahidi F. Antioxidant activity of commercial soft and hard wheat (Triticum aestivum L.) as affected by gastric $\mathrm{pH}$ conditions. J Agric Food Chem 2005;53:2433-40.

9. Madan MP, Raghavan G, Ajay KS, Prabhu P. Free radical scavenging potential of Saussarea costus. Acta Pharm 2005;55:297-304.

10. Hsu CL, Chen W, Weng YM, Tseng CY. Chemical composition, physical properties, and antioxidant activities of yam flours as affected by different drying methods. Food Chem 2003;83:85-92.

11. Stefan M, Gudrun M. Involvement of the superoxide anion radical in the autoxidation of pyrogallol and a convenient assay for superoxide dismutase. Eur J Biochem 1974;47:469-74.

12. Clark TE, Appleton CC, Drewes SE. A semi-quantitative approach to the selection of appropriate candidate of plant molluscicides - A South African application. J Ethnopharm 1997;56:1-13.

13. Marston A, Maillard M, Hostettmann K. Search for antifungal, molluscidial and larvicidal compounds from African medicinal plants. J. Ethnopharm 1993;93:215-23.

14. Sinha S, Raghuwanshi R. Phytochemical screening and antioxidant potential of Eclipta prostrata (L) L-A valuable herb. Int J Pharm Pharm Sci 2016;8:255-60.
15. Santhosh S, Velmurugan S, Annadurai R. Phytochemical screening and antimicrobial activity of medicinal plants (Eclipta prostrata L. and Sphaeranthus indicus L.). Int J Pure Appl Biosci 2015;3:271-9.

16. Saxena A, Gautam S, Kamal RA, Rama KS. Comparative study of phytochemicals, antioxidative potential and activity of enzymatic antioxidants of Eclipta alba and Plumbago zyelanica by in vitro assays. Free Radicals Antioxid 2016;6:139-144.

17. Rice-Evans C. Flavonoids and isoflavones: Absorption, metabolism and bioactivity. Free Radical Biol Med 2004;36:827-8.

18. Prior RL, Cao G. Antioxidant phytochemicals in fruits and vegetables: Diet and health implications. Hortic Sci 2000;35:588-92.

19. Pietta P, Simonetti P, Mauri P. Antioxidant activity of selected medicinal plants. J Agric Food Chem 1998;46:4487-90.

20. Rebaya A, Belghith SI, Baghdikian B, Leddet VM, Mabrouki F, Olivier E, et al. Total phenolic, total flavonoid, tannin content, and antioxidant capacity of Halimium halimifolium (Cistaceae). J Appl Pharm Sci 2014;5:52-7.

21. Crozier K, Sinclair M, Kernohan WG, Porter S. Birth technology competence: A concept analysis. Evid Based Midwifery 2006;4:96-100.

22. Blois MS. Antioxidant activity of grape seed extracts on peroxidation models in vitro. J Agri Food Chem 2001;55:1018.

23. Irda F, Kiki RR, Insanu M. In vitro antioxidant activities from various extracts of banana peels using ABTS, DPPH assays and correlation with phenolic, flavonoid, carotenoid content. Int J Pharm Pharm Sci 2014;6:299-303

24. Parul R, Kundu SK, Saha P. In vitro nitric oxide scavenging activity of methanol extracts of three Bangladeshi medicinal plants. Pharm Innov J 2013;1:83-8.

25. Ialenti A, Moncada S, Di Rosa M. Modulation of adjuvant arthritis by endogeneous nitric oxide. Br J Pharm 1993;110:701-5.

26. Enein AM, El-Baz FK, El-Baroty GS, Youssef AM, El-Baky HH. Antioxidant activity of algal extracts on lipid peroxidation. J Med Sci 2003;3:87-98.

27. Gordon MH. The mechanism of the antioxidant action in vitro. In: Hudson BJ, editor. Food Antioxidant. London: Elsevier; 1990. p. 1-18.

28. Curtis JJ, Mortiz M. Serum enzymes derived from liver cell fraction and response to carbon tetrachloride intoxication in rats. Gastroenterology 1972;62:84-92.

29. Shilpam S, Richa R. Phytochemical screening and antioxidant potential of Eclipta prostrata L-A valuable herb. Int J Pharm Pharm Sci 2016;8:255-60. 